\title{
How Morocco Succeeds in Eliminating Schistosomiasis
}

\author{
Zineb Tlamçani \\ University Hospital Center Hassan II, Fes, Morocco.,
} Corresponding Author
Zineb Tlamcani

E mail:

Tzineb@hotmail.fr

Key words: Schistosomiasis, elimination, Morocco
Schistosomiasis is an endemic parasitic infection very linked to poverty. It is considered a world health problem since it infects people from 76 different countries especially tropical and subtropical regions. For many years, Morocco was endemic for shistosome infection. The unique form is urinary schistosomiasis and the first case was described in 1914. After an alarming prevalence rate (13 416 cases) in 1973, Morocco decided to establish a strategy to control and then to eliminate schistosomiasis through three

\section{INTRODUCTION}

Schistosomiasis or bilharzia is a tropical parasitic infection due to blood-dwelling fluke worms of the genus Schistosoma [1]. It is widespread in 76 countries and territories in tropical and subtropical zones and is approximated to infect about 200 million people worldwide, leading to critical morbidity $[2,3,4]$. Schistosomiasis continue to be truly disregarded in some countries by reason of the close link with poverty, geographical isolation, underappreciated global problem, stigmatization, absence of political voice of those infected and the lack of an developed global financing system[5,6]. Schistosomiasis control strategies should be founded on four principal goals for interventions: 1) screening for infected people and killing adult worm by chemotherapy 2) acting on intermediate host "snail" by biological or chemical control and environmental management 3) preventing water contamination by using people information, education and communication (IEC), 4) prevention of human contamination by using IEC, sanitation and hygiene. The ultimate aim of all schistosomiasis interventions efforts is required to be the elimination of major phases (control, elimination and consolidation). Since 2004 and until now, it isn't reported any new indigenous case. Morocco achieves the goal and succeeds in decreasing the prevalence of infection to a level of zero so eliminating schistosomiasis in all endemic geographic areas. this infection [7]. Elimination has been accomplished in several epidemiological locations and control progress in numerous endemic areas are now in the position to work for elimination after they have efficiently reduced morbidity relating to schistosome infections. Recognition of the public health implications of schistosomiasis, political will and motivation, and continual application of the established national control programs achieved with success wherever tried as in Brazil, the People's Republic of China (P.R. China) and Egypt $[8,9]$. In this article we will take the example of Morocco to illustrate the efforts of responsible authorities in combination with World Health Organization (WHO) to fight and eliminate schistosomiasis and to achieve the goals drawn through different programs.

\section{DISCUSSION}

Schistosomiasis was endemic to rural areas in southern Morocco for many years, and the first cases were identified in 1914 [10]. The only form of schistosomiasis in Morocco is urinary schistosomiasis due to Schistosoma haematobium [11]. During the last three decades, the progression of irrigation resulted in the spread of the disease, transmitted 
by $\mathrm{B}$ truncatus, to the north and center of the country leading to ecologically diverse endemic foci: oases and arid areas; periodical streams in mountainous areas; modern irrigation strategies; coastal plains, swamps and rivers [12].

The epidemiological situation of the disease was viewed as alarming in 1973 (13 416 cases) thing witch push, three years later, the Ministry of Health to invest in a national control program. This program was launched in 1976 by a preparatory phase which lasted three years (1977-1981), followed by a test phase in three pilot provinces [13]. The preparatory phase intended for defining an appropriate strategy and operational approach to develop the national control program, and not until 1982 that it became operational in all provinces at risk of disease transmission [14].

The operational phase covering the years 1982 1993, where the adopted strategy designed to control morbidity, infection and transmission by: case-detection (selective passive detection, selective active detection, exhaustive detection, mass screening; malacological observation (snail monitoring, mollusciciding); chemotherapy (individual and mass treatment) and health education [15]. After the introduction and spread of the program in all provinces exposed, the number of cases decreased from 6,582 in 1982 to 3,887 in 1989 , with a peak of 10,645 cases in 1983[16].

This favorable evolution of the epidemiological situation of the disease was due in large part to the continuous actions of the control program, reinforced in 1987 by the introduction of praziquantel, very effective drug and administered as a single dose. By the end of 1992, certain foci of transmission had been totally inactivated; others were widely under control and prevalence was progressively falling. In 1993, a schistosomiasis elimination program (SEP) was developed [15].

The elimination phase has been started since 1994; the objective is to intensify the effort to eliminate all disease transmission foci at the end of 2004. It is based on: improving case-detection in high-risk areas; providing treatment of all detected cases and wide coverage in the case of mass chemotherapy; improving snail surveillance and mollusciciding where necessary; supporting health education; developing intersectoral action and improving intersectoral coordination; motivating community participation [15]. Moreover there was monitoring and continual evaluation of the efficiency of the interventions. Parasitological monitoring was intensive with 149,718 samples being tested in 2000, 130,826 in 2004 and 90,470 in 2006 [12].

Since 2005, the program moved into in the consolidation phase, which will continue until 2010. This has been characterized by (1) upkeep of the surveillance activities with a aim for detection in previous endemic locations and schools (children under 10 years of age enrolled or non-enrolled) to identify replaced transmission (2) epidemiological surveys around this sort of cases and mass treatment (3) Prolonged surveillance of water bodies (323 water bodies were analyzed in 2006) and control of snail hosts [12].

Since the start of the SEP, the number of cases of schistosomiasis in Morocco has been steadily reduced. In 1999, 231 cases were recorded, of which $83 \%$ reported in four provinces, and in 2002 this figure was reduced to 42 cases. No indigenous case has been noticed in the country since 2004[14]. During the period of 2005-2009, epidemiologic observations mentioned that there was an interruption of transmission at the national level. No active focus of transmission was noticed, in spite of intensified surveys within the at risk provinces. Only 13 and 4 sporadic cases were found in 2005 and 2006, respectively. Epidemiologic investigations executed around these cases affirmed that nine cases were imported, and eight cases were residual cases [10].

The epidemiological situation of Schistosomiasis in 2010 was marked by control of the situation at all foci, no cases from active transmission has been identified for the sixth consecutive year. The ministry reported just the detection of imported case from Mauritania and a residual case native of Taroudant [17]. In 2012 no indigenous or imported case was reported [18]. Figure 1 shows the evolution of the number of cases during 1994-2012. 


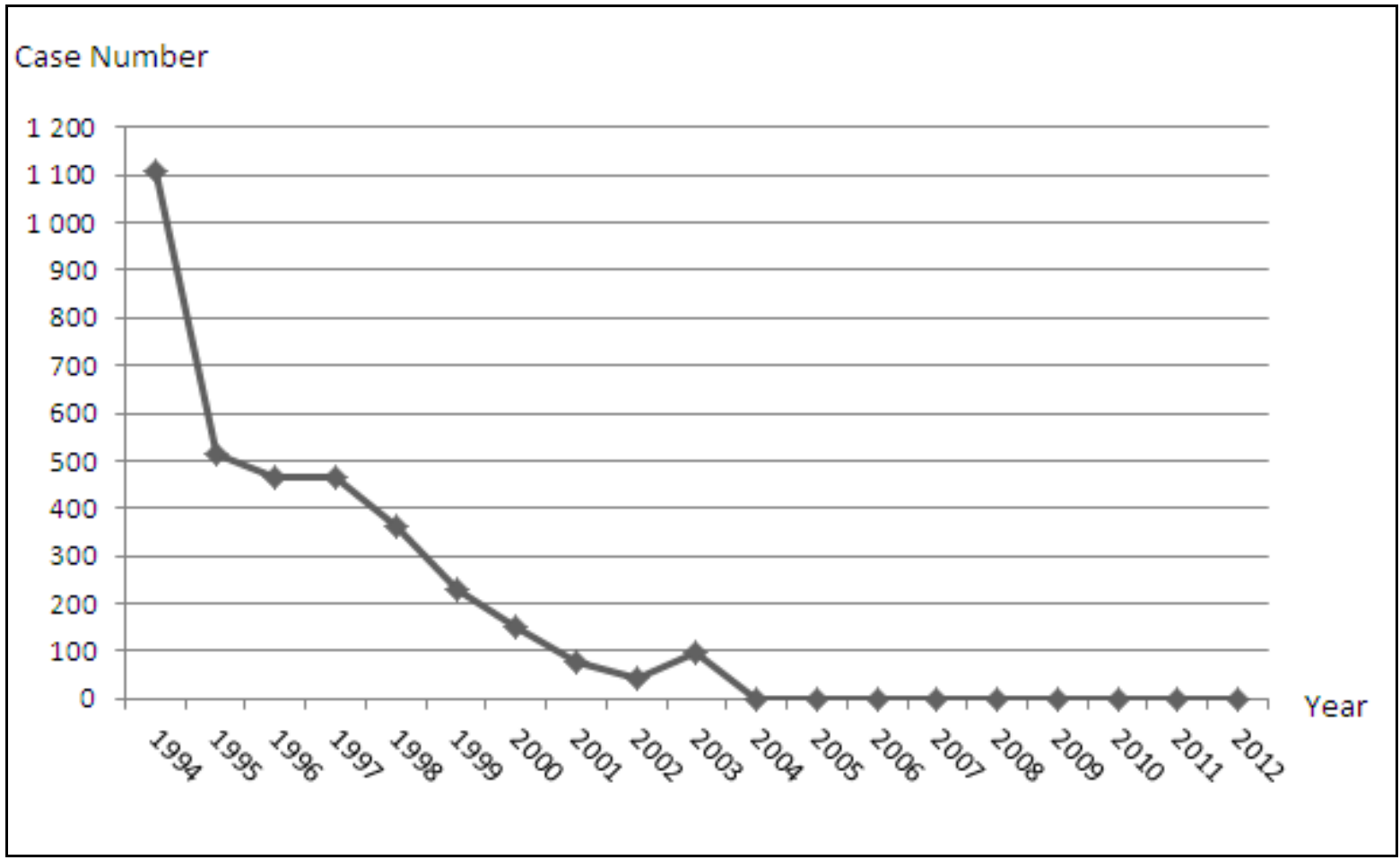

Figure 1: Evolution of schistosomiasis case number during the period of 1994-2012

We can say that Moroccan strategy was based on three major phases witch are control phase, eliminating phase and consolidation phase. The course of the Moroccan strategy is summarized in figure 2 .

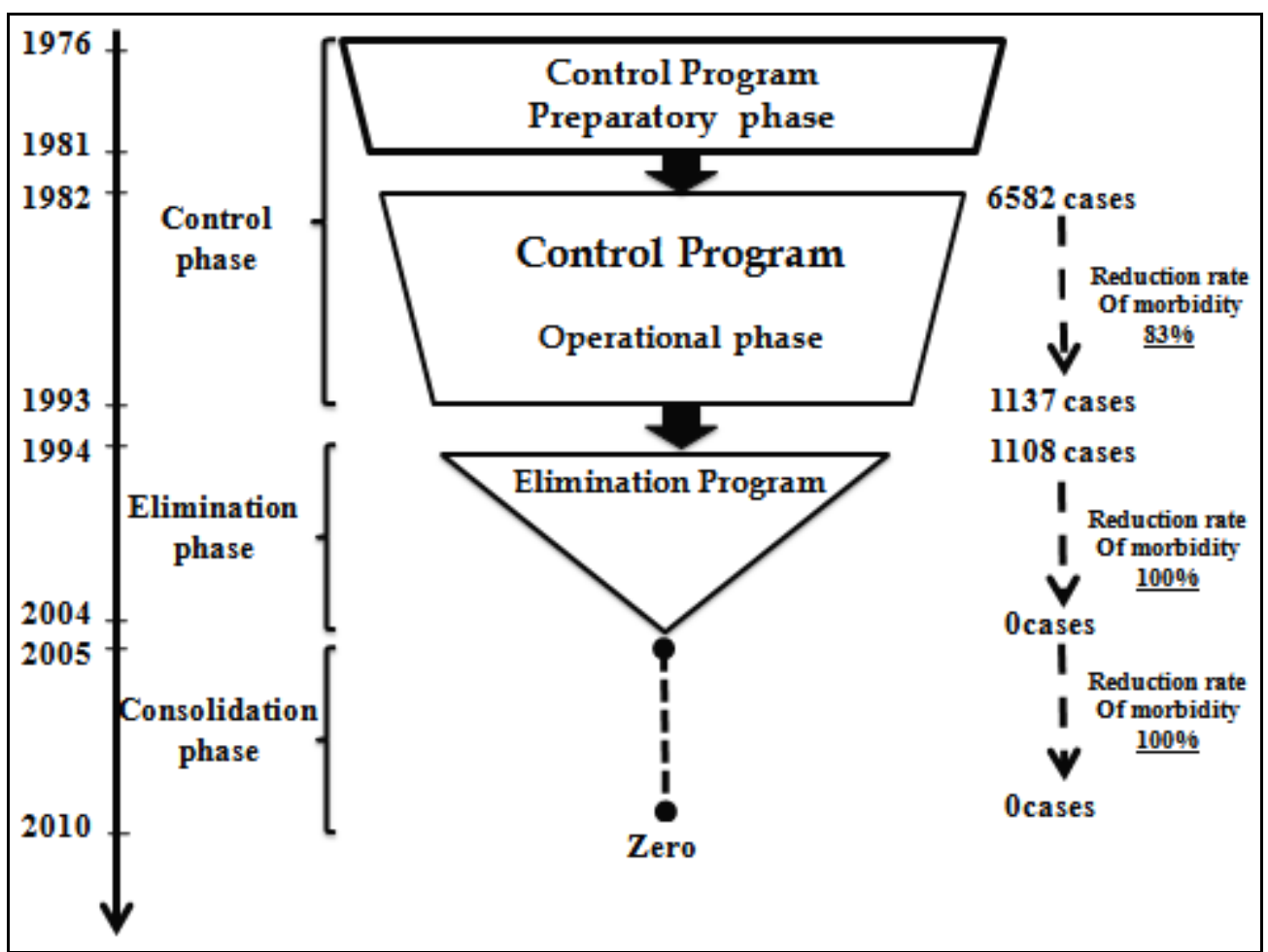

Figure 2: Moroccan strategy to control and eliminate schistosomiasis 
Another factor that influenced the schistosomiasis incidence rate was the rainfall deficit (> 20\%), which happened during 19902000 in Morocco and resulted in the natural drying of irrigation canals and a reducing in snail habitats. Moreover, infrastructure developments, including safe water supplies as a means of excreta disposal and an improved primary health care system in rural zones, presented crucial roles in schistosomiasis elimination. All of these factors contributed to decrease the prevalence and intensity of infection to a level of zero [10]. Given these results, the relevant officials at the Ministry of Health began the process of applying for certification of disease elimination from WHO.

\section{CONCLUSION}

To conclude Morocco achieves the goal and succeeds in eliminating schistosomiasis in all defined endemic geographic areas. The author acknowledges all the efforts established by Moroccan authorities and suggest to all endemic countries, with very high rate of shistosomiasis morbidity, to follow such strategy in order to control and eliminate this disease.

\section{REFERENCES}

1. Gryseels B, Polman K, Clerinx J, Kesten L: Human schistosomiasis. Lancet 2006, 368: 11061118.

2. Hodges MH, Soares Magalhaes RJ, Paye J, Koroma JB, Sonnie M, Clements A, Zhang Y: Combined Spatial Prediction of Schistosomiasis and Soil-Transmitted Helminthiasis in Sierra Leone: A Tool for Integrated Disease Control. PLoS Negl Trop Dis 2012, 6(6): e1694. doi:10.1371.

3. Chitsulo L, Engels D, Montresor A, Savioli L: The global status of schistosomiasis and its control. Acta Trop 2000, 77: 41-51.

4. Steinmann P, Keiser J, Bos R, Tanner M, Utzinger $\mathrm{J}$ : Schistosomiasis and water resources development: systematic review, meta-analysis, and estimates of people at risk. Lancet Infect Dis 2006, 6: 411-425.

5. Gray DJ, McManus DP, Li YS, Williams GM, Bergquis R, Ross AG: Schistosomiasis elimination: lessons from the past guide the future. Lancet Infect Dis 2010, 10: 733-736.

6. Payne L, Fitchett JR: Bringing neglected tropical diseases into the spotlight. Trends Parasitol 2010, 26: 421-423.
7. Stothard JR: Improving control of African schistosomiasis: towards effective use of rapid diagnostic tests within an appropriate disease surveillance model. Transactions of the Royal Society of Tropical Medicine and Hygiene 2009, 103:325-332.

8. Engels D, Chitsulo L, Montresor A, Savioli L: The global epidemiological situation of schistosomiasis and new approaches to control and research. Acta Trop 2002, 82: 139-146.

9. Wang L, Utzinger J, Zhou XN: Schistosomiasis control: experiences and lessons from China. Lancet 2008, 372: 1793-1795

10. Amarir F, El Mansouri B, Fellah H, Sebti F, Lakranbi M , Handali S, Wilkins P, Laamrani El Idrissi A, Sadak A, and Rhajaoui M: National Serologic Survey of Haematobium Schistosomiasis in Morocco: Evidence for Elimination. Am. J. Trop. Med. Hyg 2011, 84(Suppl 1):15-19

11. Doumenge JP, Mott KE: Global distribution of schistosomiasis: CEGET/WHO atlas. World Health Stat 1984, Q 37: 186 -199.

12. Anonymous: EMRO Report of Schistosomiasis. Inter-Country Meeting on Strategies to Eliminate Schistosomiasis from the Eastern Mediterranean Region. Oman . November 6-8, 2007.

13. Anonyme: Guide de la lutte contre la schistosomiase. Rabat, Ministère de la Santé, Direction des Affaires techniques, 1982.

14. Barkia H, Barkia A, Nhammi H et Belghyti D : La schistosomiase au Maroc : de sa découverte à 1'après-élimination. Eastern Mediterranean Health Journal 2011, 17(3):250-6

15. Anonymous: Report of a WHO Informal Consultation, Elimination of schistosomiasis from low-transmission areas. World Health Organization Brazil 2008, (WHO/HTM/NTD/PCT/2009.2)

16. DELM : Etat d'Avancement des Programmes de Lutte Contre les Maladies Parasitaires. Rapport Annuel d'Activités 1982 à 2002.

17. DELM : Etat d'Avancement des Programmes de Lutte Contre les Maladies Parasitaires. Rapport Annuel d'Activités 2010.

18. DELM : Etat d'Avancement des Programmes de Lutte Contre les Maladies Parasitaires. Rapport Annuel d'Activités 2012.

Peer Reviewer :Mohamad Emam:Professor of Tropical Medicine,Zagazig University,Egypt.

Editor :Tarik Zaher; Assistant Professor of Tropical Medicine,Zagazig University,Egypt 